pressure sores are superficial, so that Op-Site is an important addition to the present methods of treatment. Although its use is at present restricted to hospitals, I understand that it is being considered for prescription on EC10.

M A NASAR

Department of Clinical Gerontology St John's Hospital
London Sw11

\section{Levodopa in senile dementia}

SIR,-Further to our previous paper $(4 \mathrm{March}$, p 550) we wish to report briefly the effect of continued treatment with levodopa in five of the patients with senile dementia who had shown a favourable response in the original trial. After a break of one month $750 \mathrm{mg}$ of levodopa was given daily for a further six months. Five control patients with senile dementia matched for age and sex were selected and both groups were rated monthly on the Crichton Intellectual and Behaviora Rating Scales. The intellectual but not the behavioural rating was blind.

As in the original trial no marked changes were apparent in behavioural ratings in either drug-treated patients or controls. Although the mean intellectual scale scores declined little in the drug-free period between the original and the more extended trial, they improved again when drug therapy was resumed so that mean scores for the drugtreated group over the six-month period were comparable to the scores during the active preparation phase of the original trial. There were continued slight improvements in intellectual functioning in three out of the five experimental subjects during the six-month treatment period. Of the two patients who did not show improvement in terms of mean scores, one showed a very spectacular decline in functioning between the last two ratings and the other showed a very steady deterioration in both intellectual and behavioural function.

In conclusion, although on average the original small gains made in intellectual performance in the drug-treated group appeared to be maintained over several months, the clinical relevance of these findings may be questionable. We are doubtful whether levodopa should be recommended for the routine treatment of this condition at present.

Kate JOHNSON

A S PRESLY

Royal Dundee Liff Hospital,

B R BALLINGER

Dundee

\section{Annual General Meeting of the Royal Society of Medicine}

SIR,-May I use the courtesy of your columns to ask as many fellows of the Royal Society of Medicine as possible to come to the Annual General Meeting on 11 July to discuss the following two motions:

(1) that the Council be required to consult each individual fellow by postal circular before major policy decisions are taken, especially with regard to the society's property, journal, library, or finance;

(2) to amend Bye-law XIII.9 to read: It shall be the duty of the Executive Director to submit to the President each year, for presentation to the fellowship before the Annual General Meeting for discussion at the Annual General Meeting, a report on the activities, property, and finances of the society.

I put these forward because I believe that major changes have been made in our society without the fellows being properly consulted, however long the problems may have been discussed. I do not think it is right that major decisions should be rubber-stamped by poorly attended special meetings. Similarly I believe that, as in most other bodies, the RSM should prepare an annual report for discussion at the Annual General Meeting and not, as at present, publish it in the autumn.

W F WHIMSTER Member of the Council Pathology, RSM

London SE3

\section{GMC's finances}

SIR,-I have in an idle moment been glancing through the General Medical Council's Annual Report for 1977. I wonder how many members of the BMA are aware that of the $£ 634716$ paid in annual retention fees no less than $£, 125053\left(19 \cdot 7^{\circ}\right)$ is actually spent on their collection. Could the BMA advise the GMC how to reduce this proportion?

Incidentally, the cost of maintaining the register is only $£ 78692$.

Andover, Hants

MARY PACK

\section{Medical Act 1978}

SIR,-Dr E Kandiyali (10 June, p 1554) has expressed the anxieties of overseas doctors and particularly junior hospital doctors regarding the limited register which will be set up by the Medical Act of 1978 . We hope that we can give some reassurance.

When the new arrangements start overseas doctors already on the temporary register will fall into two groups-consultants and others. The former will have the right to full registration under the Act on the basis that they have already satisfied appointments committees of their ability to assume ultimate responsibility for a patient.

Other hospital doctors can apply for limited registration at any time up to six months from the end of their existing temporary registration. In their particular case limited registration will not be restricted to the five-year "permitted period." The transitional arrangements in part 1 of schedule 5 of the Act protect their position. In the normal course of events they will apply to the GMC for full registration. As Dr Kandiyali says, the criteria are ill defined in the Act itself; they are left to the General Medical Council.

That is in line with BMA policy, which is that the standards for registration should be set by the reformed GMC-that is, by the profession and not by Government. Doctors on the limited register will be eligible to stand for election to the GMC and to vote. Even more important, they will have the right to appeal to a Review Board for Overseas Qualified Practitioners if the GMC denies them full registration. That board must include at least one overseas graduate and the GMC must take note of its opinion.

Those doctors who come to this country after the Act is operative will know before they leave home that their limited registration will be restricted to five years, but they too will have the right to apply for full registration and to appeal.

Last year the Representative Body resolved that the BMA should seek, through a reformed GMC, a system of registration for overseas graduates which is fair in operation. Getting the Act passed was merely the first step. The law now requires the GMC and the Department of Health and Social Security to consult with the BMA and others on the various detailed rules for its working and for the conduct of elections. These must then be approved by the Privy Council or by Parliament, as the case may be.

Dr Kendiyali's presence on the working party, and our own inclination, will help to ensure that justice is done to those he represents.

Alresford, Hants

JOHN HAPPEL

JOHN MARKS Joint Chairmen,

Boreham Wood, Herts BMA Working Party on the GMC

\section{Shortage specialties: radiology}

SIR,-Dr J L C Dall (3 June, p 1489) clearly highlights the serious deficiency of academic appointments in the shortage specialties. In comparison with whole-time equivalents in general medicine and paediatric medicine he points out that only $4 \%$ of senior posts in geriatric medicine are academic appointments against $19 \%$ in each of the specialties of general medicine and paediatric medicine. $\mathrm{He}$ indicates that the problem is even more serious in radiology, where only $2 \%$ of the 736 consultants in England and Wales hold academic posts.

It is relevant to compare radiology with other service specialties and particularly with laboratory medicine. In England and Wales there are a total of 1401 consultants in pathology, haematology, biochemistry, neuropathology, etc, and $32^{\circ}{ }_{\circ}$ of these posts are academic appointments. The position is the same for senior registrars, where $5^{\%}$ of posts in radiology are academic appointments against $28^{\circ}$, in laboratory medicine, $44^{\circ}{ }_{0}^{\circ}$ in general medicine, $32 \%$ in general surgery, and $37^{\circ}$ " in paediatric medicine. ${ }^{1}$

Radiology has expanded rapidly over the years and the specialty now plays a major role in diagnosis and patient management. The specialty now includes ultrasound with its many exciting developments; nuclear medicine in some departments; and now computerised tomography. Many doctors request these sophisticated investigations and have unrestricted use of expensive resources. It is now even more important that these rapidly emerging techniques are properly and critically evaluated. Moreover, it is equally important that there is not only continuing teaching of clinicians requesting the investigations but also of trainee radiologists who will be responsible for their quality. Such evaluation and education should properly be the role of adequately funded academic departments with the necessary time and expertise.

There are many excellent young trainees in radiology who are well suited to academic careers. It is essential that they be given such an opportunity in well-funded academic departments. On a recent visit to Australasia as the Rohan Williams Travelling Professor it was alarming and of serious concern to Britain to see the large number of able UK- 